\title{
Arachidonic acid and colorectal adenoma risk: a Mendelian randomization study
}

This article was published in the following Dove Press journal:

Clinical Epidemiology

\author{
Chelsea A Isom' \\ Martha J Shrubsole ${ }^{2,3}$ \\ Qiuyin $\mathrm{Cai}^{2}$ \\ Walter E Smalley ${ }^{4,5}$ \\ Reid M Ness ${ }^{5}$ \\ Wei Zheng ${ }^{2,3}$ \\ Harvey J Murff ${ }^{3,6}$
}

'Department of General Surgery, Vanderbilt University Medical Center, Nashville, TN, USA; ${ }^{2}$ Division of Epidemiology, Vanderbilt University Medical Center, Nashville, TN, USA; ${ }^{3}$ GRECC, Department of Veterans Affairs, Tennessee Valley Healthcare System, Nashville, TN, USA ${ }^{4}$ Department of Health Policy, Vanderbilt University Medical Center, Nashville, TN, USA; ${ }^{5}$ Division of Gastroenterology, Vanderbilt University Medical Center, Nashville, TN, USA; ' Division of General Internal Medicine and Public Health, Vanderbilt University Medical Center, Nashville, TN, USA
Correspondence: Harvey J Murff

Division of General Internal Medicine and Public Health, Vanderbilt University, 2525 West End Avenue, Suite 450, Nashville, TN 37203, USA

$\mathrm{Tel}+\mathrm{I} 6159368319$

$\mathrm{Fax}+\mathrm{I} 6159361269$

Email harvey.j.murff@vanderbilt.edu
Background: Previous studies have shown a link between increased dietary intake of arachidonic acid (ARA) and colorectal neoplasms. It has been shown that erythrocyte phospholipid membrane concentrations of ARA are strongly determined by genetic variation. Fatty acid desaturase (FADS) controls the rate limiting step in ARA production, and FADS variant rs 174537 has been shown to be responsible for up to $18.6 \%$ of the variation seen. To determine if a causal association exists between erythrocyte membrane ARA concentrations and colorectal adenomas, we conducted a Mendelian randomization (MR) analysis using rs174537 as an instrumental variable (IV). MR analysis was chosen because it is less susceptible to bias and confounding. Patients and methods: A case-control study was performed using the Tennessee Colorectal Polyps Study. Patients were matched on age, gender, race, facility site, and year of colonoscopy. Cases were defined as any colorectal adenoma on colonoscopy $(n=909)$ and controls were polyp free ( $n=855)$. A two-stage logistic regression was conducted using rs174537 as the IV with the dependent variable being the presence of a colorectal adenoma on colonoscopy.

Results: Cases were older ( 59 vs 57 years of age, $P<0.0001$ ), and more likely to use alcohol ( $47.4 \%$ vs $19.8 \%, P=0.001)$ and to smoke $(77.0 \%$ vs $66.9 \%, P<0.0001)$. There was no statistically significant difference in: age, sex, alcohol use, body mass index (BMI), or NSAID use when stratified by the rs 174537 alleles. Genotype was strongly associated with erythrocyte membrane ARA concentrations $(P<0.0001)$. We found no evidence of an association between our IV (rs174537) and colorectal adenomas $(P=0.41)$.

Conclusion: In our MR study increased erythrocyte ARA concentrations were not associated with the risk of colorectal adenomas.

Keywords: arachidonic acid, Mendelian randomization, adenomas

\section{Plain language summary}

Studies have looked at what foods may be associated with an increased risk for colorectal cancer (CRC). However, it has been difficult to interpret these results as no one can remember exactly what they ate every day for years. Diet studies have suggested that people who eat food with high Arachidonic acid (ARA) content, such as red meat, may have an increased risk for CRC. It is known that CRC develops from small polyps in the colon and that is why colonoscopies are recommended to remove these polyps. Previous research has found a gene that is responsible for making ARA. This gene has different versions and person A may make more than person $B$ even if they ate the exact same diet. So, we determined what gene a person had, then looked at whether or not on a colonoscopy they had a polyp. We found that even in those people that had a gene that creates more ARA there was no increased risk 
of them having a polyp. This potentially means that eating diets high in ARA may not influence a person's cancer risk. More studies with large populations will need to be done to confirm this result.

\section{Introduction}

Colorectal cancer (CRC) is the fourth most common cancer diagnosis in the United States and the second most common cause of cancer-related death. ${ }^{1}$ Several dietary studies have shown an increase in CRC risk with diets that are high in the n-6 polyunsaturated fatty acid, arachidonic acid (ARA). ${ }^{2,3} \mathrm{~A}$ possible mechanism linking ARA to $\mathrm{CRC}$ is that the proinflammatory eicosanoid prostaglandin $(\mathrm{PG}) \mathrm{E}_{2}$ is derived from ARA through the cyclooxygenase pathway and is often found to be overproduced in colorectal neoplasms. ${ }^{4}$ In preclinical models, increasing tissue levels of ARA are correlated with increase in $\mathrm{PGE}_{2}$ production as well as intestinal tumor numbers. ${ }^{5-10}$ In human observational studies, high erythrocyte membrane concentration of ARA has also been linked to increased risk for colorectal polyps, which seems to support these preclinical findings. ${ }^{4}$

Observational studies of self-reported dietary ARA levels can be prone to bias, confounding, and reverse causation. Tissue levels of ARA represent both exogenous ARA, from dietary sources, as well as endogenously produced ARA. ${ }^{11,12}$ Endogenously produced ARA is derived from linoleic acid with the rate limiting enzyme in this conversion being fatty acid desaturase (FADS). ${ }^{13}$ Multiple genome-wide association studies (GWAS) have confirmed that FADS activity influences the amount of circulating ARA. ${ }^{12,14-16}$ The single nucleotide polymorphism (SNP) rs174537 explains up to $18.6 \%$ of the additive variance in circulating ARA levels and shows a dose-dependent increase in ARA levels with each $\mathrm{G}$ allele. ${ }^{14}$

To determine the role that ARA has in colorectal polyp risk, we conducted a Mendelian randomization (MR) study to minimize the issues of confounding, reverse causation, and reporting bias. MR is founded on the principle that alleles are randomly assorted at conception and should not be influenced by environmental and lifestyle factors. Identification of a genetic factor (rs174537) that is associated with the risk factor (ARA) can serve as the instrumental variable (IV) and be a proxy for lifelong exposure. ${ }^{17} \mathrm{We}$, therefore, wanted to determine the causal association between elevated ARA concentrations in erythrocyte membranes and risk of developing colorectal polyps using case-control data.

\section{Patients and methods}

For this study, we used data collected as part of the Tennessee Colorectal Polyp Study for which the methods have been previously published. ${ }^{18,19}$ In brief, this study was conducted at the Vanderbilt Gastroenterology Clinic between February 1, 2003 and April 1, 2010 and at the Veterans' Affair Tennessee Valley Health System Nashville campus between August 21, 2003 and May 30, 2007. Participants aged 40-75 years undergoing colonoscopy examination were recruited. Patients were excluded if they had: genetic CRC syndromes, history of inflammatory bowel disease, prior history of adenomatous polyps, or any cancer other than nonmelanoma skin cancer. Of the 12,585 potentially eligible individuals, 7,621 patients provided written consent. Cases and controls were matched on age \pm 5 years, race, gender, facility site, and time of colonoscopy \pm 90 days. Cases were defined as one or more polyps on colonoscopy confirmed by pathology, and controls were polyp free on a complete colonoscopy. A trained interviewer conducted a standardized telephone interview after colonoscopy to obtain information on medication use, demographics, medical history, family history, reproductive history, and lifestyle. Patients were designated as current NSAID user if they took an NSAID at least 3 days a week, every week for the last 2 months. They were defined as regular alcohol consumers if they had at least five drinks a week for the last 12 months. This study was approved by the Vanderbilt University Institutional Review Board, the Veterans' Affairs Institutional Review Board, and the Veterans' Affairs Research and Development Committee. All patients provided written informed consent in accordance with the Declaration of Helsinki.

Participants were asked to donate a $15-\mathrm{mL}$ fasting blood sample. Whole blood was separated into plasma, buffy coats (white cells), and red blood cells, while viable lymphocytes were retained (heparin tube). Samples were processed within 6 hours of collection and stored for future analyses in a $-80^{\circ} \mathrm{C}$ freezer. Erythrocyte membrane phospholipid fatty acid concentrations were determined by gas chromatography using the method described by Folch et al. ${ }^{20,21}$ Inclusion of the internal standard, dipentadecanoyl phosphatidylcholine (C15:0), permitted quantitation of the amount of phospholipid in the sample. ARA concentrations are presented as percentage of total RBC membrane phospholipid fatty acid content. Laboratory staff was blinded to case-control status and any other information on study subjects.

Genomic DNA was extracted from buffy coat fractions using the QIAamp Blood Kit (Qiagen NV, Venlo, the Netherlands) following the manufacturer's protocol. SNP rs174537 
was genotyped using the iPLEX Sequenom MassArray platform as part of a large genotype study. Included in each 96-well plate as quality control samples were one negative control (water), two blinded duplicates, and two HapMap samples. The concordance rate was $100 \%$ for both blinded duplicates and HapMap samples. The genotype distribution for rs 174537 was in Hardy-Weinberg equilibrium.

Genotypic data and erythrocyte phospholipid membrane concentrations were available on 1,933 patients, consisting of 942 controls and 991 cases. To estimate the causal OR we used the two-stage approach for MR. ${ }^{23}$ Using this two-stage approach for a binary outcome, with a total sample size of 1764, $a=0.05, \mathrm{~K}=0.52$, expected $\mathrm{OR}$ of 1.6 , and variance of 0.18 , we have $99 \%$ power to detect a difference. ${ }^{4,14}$ The IV was the SNP rs 174537 coded as 0,1 , and $2(0=\mathrm{TT}, 1=\mathrm{GT}$, $2=\mathrm{GG})$. The phenotype was the percentage of erythrocyte membrane fatty acid content that was composed of ARA, as a continuous variable. In step one, a linear regression was performed on the phenotype (ARA level) and IV (rs174537). From this regression, the residuals were estimated. The second stage was a logistic regression of the outcome, binary case vs control, and the residuals from stage one. The goal of the first step is to minimize any unmeasurable confounding factors.

We also conducted a secondary analysis repeating the two-stage MR, where the GT and TT allele were combined into a single reference group, given that the TT alleles are less common. For comparison of continuous variables, the Student $t$-test and ANOVA were used. For categorical variable comparison the chi-squared test was used. All statistics were performed using Stata version 14.2.

\section{Results}

Cases were older ( $58.9 \pm 7.2$ vs $56.6 \pm 7.1)$, were more likely to be smokers ( $77.0 \%$ vs $66.9 \%)$, and current alcohol users ( $47.4 \%$ vs $19.8 \%$ ) compared to controls (Table 1). Between the cases and controls there was no statistically significant difference in gender, race, site of colonoscopy, BMI, or reason for colonoscopy.

When the cohort was stratified by rs174537 alleles there was a statistically significant rise in ARA erythrocyte membrane concentrations with the addition of the $G$ allele (Table 2). Between the allele groups the only statistically significant difference was race, with the TT genotype being less common in African-Americans compared to whites (Table 3).

The stage one linear regression of ARA levels against rs174537 SNP, using TT as the reference, gave a coefficient of 0.74 , with an F statistic of $31.49, P<0.0001$. The logistic regression performed used the TT allele as a reference and
Table I Baseline characteristics for patients based on case status

\begin{tabular}{|c|c|c|c|}
\hline & $\begin{array}{l}\text { Cases, }^{a} \\
\mathrm{n}=909\end{array}$ & $\begin{array}{l}\text { Controls, } \\
n=855\end{array}$ & $P$-value \\
\hline Age, years (mean $\pm S D$ ) & $58.9 \pm 7.2$ & $56.6 \pm 7.1$ & $<0.000$ I \\
\hline Sex, \% female & 25.2 & 26.0 & 0.62 \\
\hline \multicolumn{4}{|l|}{ Race, \% } \\
\hline White & 91.9 & 92.2 & 0.88 \\
\hline African-American & 6.5 & 6.1 & \\
\hline Other & 1.7 & 1.8 & \\
\hline \multicolumn{4}{|l|}{ Alcohol use, \% } \\
\hline Current & 47.4 & 19.8 & 0.001 \\
\hline Former & 27.7 & 23.4 & \\
\hline Never & 24.6 & 56.5 & \\
\hline Unknown & 0.2 & 0.4 & \\
\hline Current smokers, \% & 77.0 & 67.0 & $<0.0001$ \\
\hline Facility site, \% Vanderbilt & 63.3 & 64.4 & 0.64 \\
\hline $\mathrm{BMI}($ mean $\pm \mathrm{SD}), \mathrm{kg} / \mathrm{m}^{2}$ & $28.4 \pm 5.15$ & $28.1 \pm 5.28$ & 0.24 \\
\hline \multicolumn{4}{|l|}{ Screening reason, $\%$} \\
\hline Yearly screening & 58.9 & 58.3 & 0.60 \\
\hline Family history & 10.8 & 12.6 & \\
\hline Diagnostic/bleeding/follow-up & 21.9 & 20.8 & \\
\hline Other & 8.5 & 8.3 & \\
\hline Unknown & 0 & 0 & \\
\hline \multicolumn{4}{|l|}{ NSAIDS, \% } \\
\hline Never & 42.7 & 38.3 & 0.05 \\
\hline Former & 6.9 & 7.6 & \\
\hline Current & 49.4 & 53.9 & \\
\hline Unknown & 1.0 & 0.2 & \\
\hline
\end{tabular}

Notes: a Case is a patient with a pathologically confirmed adenoma on colonoscopy. ${ }^{b}$ Control has no adenoma on colonoscopy.

Abbreviation: BMI, body mass index.

Table 2 rs 174537 allele and erythrocyte ARA concentration

\begin{tabular}{|c|c|c|}
\hline Alleles & ARA concentration ${ }^{\mathrm{a}}(\%)$ & $P$-value \\
\hline GG & $16.71 \pm 3.68$ & $<0.000 \mathrm{I}^{\mathrm{b}}$ \\
\hline GT & $15.95 \pm 3.77$ & \\
\hline TT & $15.25 \pm 3.19$ & \\
\hline
\end{tabular}

Notes: aARA concentrations are displayed as the mean \pm SD. The concentration is the percentage of erythrocyte phospholipid membrane that is made of up ARA. ${ }^{\mathrm{D} A N O V A}$ test.

Abbreviation: ARA, arachidonic acid.

yielded an OR for an increased risk of colorectal adenoma of 1.24 (95\% CI: 0.90-1.71) for the GT allele and 1.07 (95\% CI: $0.97-1.02)$ for the GG allele $(P=0.41)$ (Table 4). Combining the GT and TT alleles into one reference group yielded an OR of 0.99 (95\% CI: $0.98-1.03)(P=0.99)$.

\section{Discussion}

In our case-control study we found no statistically significant association between elevated erythrocyte membrane ARA concentrations and colorectal polyps. There was a statistically significant dose increase in the ARA levels with the $G$ allele of SNP rs1744537, which has been reported in previous 
Table 3 Baseline characteristics stratified by allele

\begin{tabular}{|c|c|c|c|c|}
\hline & GG $n=804$ & GT $n=774$ & TT $n=186$ & $P$-value \\
\hline Age, years (mean $\pm S D$ ) & $57.5 \pm 7.02$ & $57.9 \pm 7.46$ & $58.5 \pm 7.16$ & 0.221 \\
\hline Sex, \% female & 27.1 & 24.4 & 23.7 & 0.386 \\
\hline \multicolumn{5}{|l|}{ Race, \% } \\
\hline White & 86.8 & 96.4 & 96.2 & $<0.000 I^{*}$ \\
\hline African-American & 11.2 & 2.6 & 0.5 & \\
\hline Other & 2.0 & 1.03 & 3.2 & \\
\hline \multicolumn{5}{|l|}{ Alcohol use, \% } \\
\hline Current & 20.9 & 23.9 & 21.5 & 0.525 \\
\hline Former & 27.5 & 24.0 & 24.2 & \\
\hline Never & 51.2 & 51.9 & 53.8 & \\
\hline Unknown & 0.4 & 0.1 & 0.5 & \\
\hline $\mathrm{BMI}($ mean $\pm \mathrm{SD}), \mathrm{kg} / \mathrm{m}^{2}$ & $28.1 \pm 5.05$ & $28.4 I \pm 5.30$ & $28.5 \pm 5.58$ & 0.40 \\
\hline \multicolumn{5}{|l|}{ NSAIDS, \% } \\
\hline Never & 42.5 & 39.0 & 38.2 & 0.623 \\
\hline Former & 7.7 & 6.9 & 7.0 & \\
\hline Current & 49.1 & 53.6 & 53.8 & \\
\hline Unknown & 0.6 & 0.5 & 1.1 & \\
\hline
\end{tabular}

Note: *Indicates a statistically significant $P$-value.

Abbreviation: BMI, body mass index.

Table 4 OR for colorectal adenoma by allele

\begin{tabular}{|l|l|l|}
\hline Alleles & OR $(95 \% \mathrm{CI})$ & $P$-value \\
\hline GG & $1.07(0.97-I .02)$ & $0.4 \mathrm{I}^{\mathrm{a}}$ \\
GT & $1.24(0.9-1.7 \mathrm{I})$ & \\
TT & 1.00 (reference) & \\
\hline
\end{tabular}

Notes: ${ }^{a} A$ two-stage MR analysis was performed to determine the relationship between the rs 174537 allele and colorectal adenomas.

Abbreviation: MR, Mendelian randomization.

studies. $^{12,14,15}$ There were no significant differences in the association between the allele groups and all confounding factors with the exception of race. As reported by Mathias et al, African-American patients were more likely to have a $\mathrm{G}$ allele compared to whites and have higher circulating ARA levels. ${ }^{24}$

Previous studies using diet or direct measurement of ARA and its relationship to colorectal polyps have shown conflicting results. ${ }^{4,18}$ We were unable to demonstrate an association between elevated erythrocyte ARA concentrations and colorectal adenomas using our MR design. Prior studies have shown that an increase in erythrocyte membrane percentage of ARA levels was associated with a colorectal adenoma OR of $1.66(1.05-2.62) .{ }^{4}$ One possible reason for the discrepant findings could be secondary to confounding factors associated with erythrocyte ARA concentrations, which were better minimized using the MR design. Alternatively our null result may be related to the study power. We had $85 \%$ power to detect an OR as low as 1.4 with our fixed sample size, while the effect size was reasonable given prior published work. There could be a smaller association that we were unable to detect. ${ }^{14}$
Our results differ from a previously published MR analysis conducted by May-Wilson et al who used the Cohort for Heart and Aging in Genomic Epidemiology (CHARGE) consortium. ${ }^{25}$ This study used SNP rs 174537 as the IV and CRC as the outcome. This paper found a statistically significant effect of ARA levels on CRC risk, however, the effect size was small (OR $=1.05$; 95\% CI: 1.02 , 1.07) and much weaker than our a priori estimated effect size. Although different SNPs were used for both studies, the variants are in almost complete linkage disequilibrium $\left(\mathrm{R}^{2}=0.98\right)$. Thus if our hypothesis was correct, our null findings may be explained by a low effect size of ARA on colorectal neoplasm risk. Also given that we are looking at the cancer precursor there is likely some dilution of the effect of ARA on CRC risk. Further support for the role of ARA in CRC in humans is provided by a large-scale GWAS in East Asians that found variants in FADS to be associated with $\mathrm{CRC}$ risk and with $F A D S$ gene expression in tumors and other tissues. ${ }^{22}$

One of the strengths of this study is the use of MR for analysis, which uniquely allows us to control for reverse causation, measurement bias, and confounding. It is based on several underlying assumptions, which we were able to meet. ${ }^{23}$ First is that the variant rs 174537 is robustly associated with the exposure (ARA), which was confirmed by our data and multiple studies. ${ }^{12,14-16}$ Second is that the variant is not related to confounding factors, which was consistent with our data. However, race, which is a risk factor for CRC, was associated with genotype. The strong genotype-phenotype association between $F A D S$ variants and circulating fatty 
acids has allowed this gene to be utilized as an IV in five MR studies to date. ${ }^{25-29}$

The study does have several limitations. This study used a one-time erythrocyte membrane fatty acid concentration to determine the ARA content. While using erythrocyte membrane, ARA percentage instead of ARA plasma levels would represent a longer exposure period (3-4 months vs days), within the context of CRC, this exposure timeframe is still brief. Each patient underwent a colonoscopy to detect their polyps, which is the gold standard for detection, but it was only a one-time exam and not a lifetime risk. This could lead to dilution of the ARA effect, as those patients who are polyp free now may have future adenomas. Supplemental n-3 Long chain polyunsaturated fatty acid (LCPUFAs) and possibly statin medications might influence RBC membrane ARA concentrations, and we did not have data on the use of these medications. ${ }^{30}$ An additional weakness was that we found allele frequencies were different based on African-American race, which is a known confounding variable related to CRC. This violated one of the fundamental assumptions of MR. In our sample, race was not associated with case-state, and only a small percentage of the study population were AfricanAmerican. Nevertheless, it is unclear if this finding could have influenced our results. Finally, our study may have been underpowered. This study was initially designed using the effect sizes described within the literature between circulating ARA and colorectal adenoma risks. ${ }^{4}$ Subsequently, a recent MR study reports a much weaker effect between the genetically-determined ARA and CRC risk. ${ }^{25}$

\section{Conclusion}

In conclusion, we found no evidence of an association between elevated ARA erythrocyte membrane content and risk of colorectal polyps in this MR study. If ARA is be associated with colorectal neoplasm risk, this effect is likely very modest.

\section{Acknowledgments}

DNA sample preparation and genotyping assays were performed at the Survey and Biospecimen Shared Resource, which is supported in part by the Vanderbilt-Ingram Cancer Center (P30CA068485). Fatty acid measurements were made in the Diabetes Research Training Center Lipid Sub core, supported in part by DK 020593. The content of this paper is solely the responsibility of the authors and does not necessarily represent the official views of the National Cancer Institute or the National Institutes of Health. A portion of the participants were studied as the result of resources and the use of facili- ties at the VA Tennessee Valley Healthcare System. We thank Regina Courtney and Jie Wu for their laboratory support.

This paper was accepted to the Society of Surgical Oncology $71^{\text {st }}$ Annual Cancer Symposium and its abstract was published in Annals of Surgical Oncology, February 2018, Volume 25, Supplement 1 . This study was additionally supported through the National Institute of Health grants P50CA95103, R01CA97386, R01CA143288, R01CA160938, and R01HL106845.

\section{Disclosure}

Chelsea A Isom was supported by NCI Institutional NRSA Postdoctoral Training Grant (T32 CA106183). The authors report no other conflicts of interest in this work.

\section{References}

1. Nation Cancer Institute: Surveillance, Epidemiology, and End Results. Cancer statistics. Available from: https://seer.cancer.gov/statfacts/html/ colorect.html. Accessed January 12, 2017.

2. Nkondjock A, Shatenstein B, Maisonneuve P, Ghadirian P. Assessment of risk associated with specific fatty acids and colorectal cancer among French-Canadians in Montreal: a case-control study. Int J Epidemiol. 2003;32(2):200-209.

3. Murff HJ, Shu XO, Li H, et al. A prospective study of dietary polyunsaturated fatty acids and colorectal cancer risk in Chinese women. Cancer Epidemiol Biomarkers Prev. 2009;18(8):2283-2291.

4. Rifkin SB, Shrubsole MJ, Cai Q, et al. PUFA levels in erythrocyte membrane phospholipids are differentially associated with colorectal adenoma risk. Br J Nutr. 2017;117(11):1615-1622.

5. Fan YY, Callaway E, M. Monk J, et al. A new model to study the role of arachidonic acid in colon cancer pathophysiology. Cancer Prev Res. 2016;9(9):750-757.

6. Jones R, Adel-Alvarez LA, Alvarez OR, Broaddus R, Das S. Arachidonic acid and colorectal carcinogenesis. Mol Cell Biochem. 2003;253(1-2):141-149.

7. Hansen-Petrik MB, Mcentee MF, Jull B, Shi H, Zemel MB, Whelan J. Prostaglandin $\mathrm{E}(2)$ protects intestinal tumors from nonsteroidal antiinflammatory drug-induced regression in $\mathrm{Apc}(\mathrm{Min} /+)$ mice. Cancer Res. 2002;62(2):403-408.

8. Kawamori T, Uchiya N, Sugimura T, Wakabayashi K. Enhancement of colon carcinogenesis by prostaglandin E2 administration. Carcinogenesis. 2003;24(5):985-990.

9. Petrik MB, Mcentee MF, Chiu CH, Whelan J. Antagonism of arachidonic acid is linked to the antitumorigenic effect of dietary eicosapentaenoic acid in Apc(Min/+) mice. J Nutr. 2000;130(5):1153-1158.

10. Petrik MB, McEntee MF, Johnson BT, Obukowicz MG, Whelan J. Highly unsaturated (n-3) fatty acids, but not alpha-linolenic, conjugated linoleic or gamma-linolenic acids, reduce tumorigenesis in $\mathrm{Apc}(\mathrm{Min} /+)$ mice. $J$ Nutr. 2000;130(10):2434-2443.

11. Porenta SR, Ko YA, Raskin L, et al. Interaction of fatty acid genotype and diet on changes in colonic fatty acids in a Mediterranean diet intervention study. Cancer Prev Res. 2013;6(11):1212-1221.

12. Cui T, Hester AG, Seeds MC, et al. Impact of genetic and epigenetic variations within the FADS cluster on the composition and metabolism of polyunsaturated fatty acids in prostate cancer. Prostate. 2016;76(13):1182-1191.

13. Howard TD, Mathias RA, Seeds MC, et al. DNA methylation in an enhancer region of the FADS cluster is associated with FADS activity in human liver. PLoS One. 2014;9(5):e97510.

14. Tanaka T, Shen J, Abecasis GR, et al. Genome-wide association study of plasma polyunsaturated fatty acids in the InCHIANTI Study. PLoS Genet. 2009;5(1):e1000338. 
15. Hester AG, Murphy RC, Uhlson CJ, et al. Relationship between a common variant in the fatty acid desaturase (FADS) cluster and eicosanoid generation in humans. J Biol Chem. 2014;289(32):22482-22489.

16. Rahbar E, Ainsworth HC, Howard TD, et al. Uncovering the DNA methylation landscape in key regulatory regions within the FADS cluster. PLoS One. 2017;12(9):e0180903.

17. Lawlor DA, Harbord RM, Sterne JA, Timpson N, Davey Smith G. Mendelian randomization: using genes as instruments for making causal inferences in epidemiology. Stat Med. 2008;27(8):1133-1163.

18. Murff HJ, Shrubsole MJ, Cai Q, et al. Dietary intake of PUFAs and colorectal polyp risk. Am J Clin Nutr. 2012;95(3):703-712.

19. Shrubsole MJ, Wu H, Ness RM, ShyrY, Smalley WE, Zheng W. Alcohol drinking, cigarette smoking, and risk of colorectal adenomatous and hyperplastic polyps. Am J Epidemiol. 2008;167(9):1050-1058.

20. Folch J, Lees M, Sloane Stanley GH. A simple method for the isolation and purification of total lipides from animal tissues. J Biol Chem. 1957;226(1):497-509.

21. Morrison WR, Smith LM. Preparation of fatty acid methyl esters and dimethylacetals from lipids with boron fluoride-methanol. J Lipid Res. 1964;5:600-608.

22. Zhang B, Jia WH, Matsuda K, et al. Large-scale genetic study in East Asians identifies six new loci associated with colorectal cancer risk. Nat Genet. 2014;46(6):533-542.

23. Palmer TM, Sterne JA, Harbord RM, et al. Instrumental variable estimation of causal risk ratios and causal odds ratios in Mendelian randomization analyses. Am J Epidemiol. 2011;173(12):1392-1403.
24. Mathias RA, Sergeant S, Ruczinski I, et al. The impact of FADS genetic variants on $\omega 6$ polyunsaturated fatty acid metabolism in African Americans. BMC Genet. 2011;12(1):50.

25. May-Wilson S, Sud A, Law PJ, et al. Pro-inflammatory fatty acid profile and colorectal cancer risk: A Mendelian randomisation analysis. Eur J Cancer. 2017;84:228-238.

26. Khankari NK, Murff HJ, Zeng C, et al. Polyunsaturated fatty acids and prostate cancer risk: a Mendelian randomisation analysis from the PRACTICAL consortium. Br J Cancer. 2016;115(5):624-631.

27. Lauritzen L, Sørensen LB, Harsløf LB, et al. Mendelian randomization shows sex-specific associations between long-chain PUFA-related genotypes and cognitive performance in Danish schoolchildren. Am J Clin Nutr. 2017;106(1):88-95.

28. Sallis H, Steer C, Paternoster L, Davey Smith G, Evans J. Perinatal depression and omega-3 fatty acids: a Mendelian randomisation study. $J$ Affect Disord. 2014;166:124-131.

29. Kröger J, Zietemann V, Enzenbach C, et al. Erythrocyte membrane phospholipid fatty acids, desaturase activity, and dietary fatty acids in relation to risk of type 2 diabetes in the European Prospective Investigation into Cancer and Nutrition (EPIC)-Potsdam Study. Am J Clin Nutr. 2011;93(1):127-142.

30. Risé P, Pazzucconi F, Sirtori CR, Galli C. Statins enhance arachidonic acid synthesis in hypercholesterolemic patients. Nutr Metab Cardiovasc Dis. 2001;11(2):88-94.
Clinical Epidemiology

\section{Publish your work in this journal}

Clinical Epidemiology is an international, peer-reviewed, open access, online journal focusing on disease and drug epidemiology, identification of risk factors and screening procedures to develop optimal preventative initiatives and programs. Specific topics include: diagnosis, prognosis, treatment, screening, prevention, risk factor modification,

Submit your manuscript here: https://www.dovepress.com/clinical-epidemiology-journa

\section{Dovepress}

systematic reviews, risk and safety of medical interventions, epidemiology and biostatistical methods, and evaluation of guidelines, translational medicine, health policies and economic evaluations. The manuscript management system is completely online and includes a very quick and fair peer-review system, which is all easy to use. 